\title{
PROGNOSTIC VALUE OF CIRCUMFLEX ARTERY MOTION AS A MEASUREMENT OF LEFT VENTRICULAR LONG-AXIS SYSTOLIC FUNCTION IN PATIENTS TREATED WITH PERCUTANEOUS CORONARY INTERVENTION
}

\author{
Ahmad shafie Ammar, Mohamed M. Al-Daydamony, Mohammad El-tahlawi, Ismail Mohamed \\ Cardiology Department, Faculty of Medicine-Zagazig University, Egypt
}

\begin{abstract}
Background: Accurate assessment of LV systolic function during primary PCI can help to optimize reperfusion strategies and has many prognostic implications. Circumflex artery motion (CAM) can be measured during primary PCI to reflect LV long-axis function which is an accurate indicator of LV systolic function.

Aim of the work: to test the validity of CAM as a measurement of LV long-axis systolic function in anterior STEMI patients treated with primary PCI and to determine its prognostic value.

Patients and Methods: CAM was measured using coronary angiography during primary PCI in 50 STEMI patients. Echocardioghraphic (M-mode, tissue Doppler and speckle-tracking) assessment of LV long-axis systolic function was performed within 24 hours after primary PCI. Follow-up echocardiography was scheduled after 6 months. Reverse remodeling was defined as a reduction $>10 \%$ in LV end-systolic volume by the end of follow-up period.

Results: Strong correlation was found between CAM and echocardiographic parameters of LV long-axis systolic function ( $\mathrm{p}$ for each < 0.001) as well as LVEF ( $\mathrm{r}=0.845$, $\mathrm{p}<0.001) 24$ hours after successful primary PCI. Patients were dichotomized according to the median value of CAM (median CAM: $13.9 \mathrm{~mm}$ ). Supra-median CAM was associated with higher LVEF (56.0 \pm 7.4 vs. $42.6 \pm 3.6, \mathrm{p}<0.001)$, lower peak troponin $(6.43 \pm 2.6$ vs. $11.13 \pm 2.78 \mathrm{ug} / \mathrm{L}, \mathrm{p}<0.001)$ and lower incidence of composite major adverse cardiac events (3.8\% vs. $45.8 \%, \mathrm{p}=0.001)$. A CAM cutoff value of 10.8 $\mathrm{mm}$ (sensitivity $96 \%$ and specificity $100 \%$ ) accurately predicted reverse remodeling at 6 months.

Conclusion: CAM measured at the time of primary PCI can predict LV systolic function loss, adverse clinical outcome and reverse remodeling in STEMI patients. Thus it can gauge the choice of reperfusion strategy and adjunctive therapy. Key Words: CAM (circumflex artery motion), LV long-axis systolic function, primary PCI.
\end{abstract}

\section{INTRODUCTION}

$S^{\mathrm{i} i}$ ince the time of Leonardo da Vinci, the importance of Left ventricular (LV) long-axis function has been described (1). During a single cardiac cycle, shortening, thickening, and torsion of the LV occur (2). Shortening is mediated by movement of the atrio-ventricular plane (AVP) toward the apex; the latter is relatively fixed (3). Without this long-axis shortening, normal sarcomere contraction would lead to an ejection fraction of less than $30 \%$ (4). Depressed LV longaxis function correlates with severity and prognosis of many cardiovascular diseases and it is an early indicator of subclinical systolic dysfunction (5). Being mediated by subendocardial fibers, LV long-axis function is affected early in ST elevation myocardial infarction (STEMI) and recovers early with successful reperfusion $(6,7)$.

When performed rapidly by an experienced team, primary PCI restores epicardial as well as myocardial perfusion (8), limits infarct size, reverses LV dysfunction and reduces mortality (9). At time of performing primary PCI, prediction of reverse remodeling is of utmost importance because it helps optimizing therapeutic strategies, e.g. the use of glycoprotein (GP) IIb/IIIareceptor inhibitors; thrombectomy and total revascularization are justified in patients with low potential of reverse remodeling. Reverse remodeling after primary PCI occurs more likely with effective microvascular circulation within the infarct zone (10, 11), small infarct size (12), restoration of normal LV mechanics and synchronicity $(13,14)$ and short ischemic time $(10,15)$.

Studies in patients with STEMI found that LV long-axis function accurately predicts final infarct size (16), microvascular perfusion (17), extent of myocardial viability (18) and LV remodeling and major adverse cardiac events (MACE), such as congestive heart failure and death (19).

As one part of the circumflex $(\mathrm{Cx})$ artery runs in the AV groove, this part is assumed to represent the AVP. Cx artery motion (CAM) (20) can be used to measure LV long-axis function at time of primary PCI. This allows rapid patient triage on the catheterization table without neither prolonging the door-to-balloon time nor the need of "in-lab" echocardiography machine.

The aim of this study is to determine the correlation between CAM and echocardiographic parameters of long-axis as well as global LV systolic function in patients with anterior STEMI and to determine the value of CAM in predicting LV reverse remodeling after successful primary PCI.

\section{PATIENTS AND METHODS}

Our study was performed in the faculty of medicine, Zagazig University Hospital, during the period from May 2012 to June 2014. It included 50 patients with first STEMI diagnosed by typical ischemic chest pain lasting more than 30 minutes associated with persistent ST segment elevation > 
$2 \mathrm{~mm}$ in two or more of V1 through V6 leads. Duration of chest pain shouldn't exceed 24 hours and the coronary anatomy should suitable for primary PCI of the infarct related artery (IRA). The following patients were not included in the study: history of previous MI, previous revascularization, atrial fibrillation(AF) rhythm, complete left bundle branch block (LBBB) or pacemaker, coexistence of other significant cardiac disorders (valvular lesions, cardiomyopathies), patients without identifiable apical branches of left anterior descending (LAD) artery, patients with totally occluded $\mathrm{Cx}$ artery, angiographically unsuccessful PCI defined as antegrade TIMI flow $<3$ and/or $>30 \%$ residual stenosis of the IRA and patients with poor echocrdiographic windows.

\section{All patients were subjected to:}

1. Complete history taking with emphasis on cardiac risk factors including hypertension, smoking, diabetes mellitus and hypercholesterolemia.

2. Full clinical assessment with special attention to hemodynamic parameters.

3. Electrocardiography (ECG) on admission and 90 minutes after primary PCI.

4. Laboratory work-up including creatine kinase-myocardial band (CK-MB) and troponin I on admission and serially every iii-

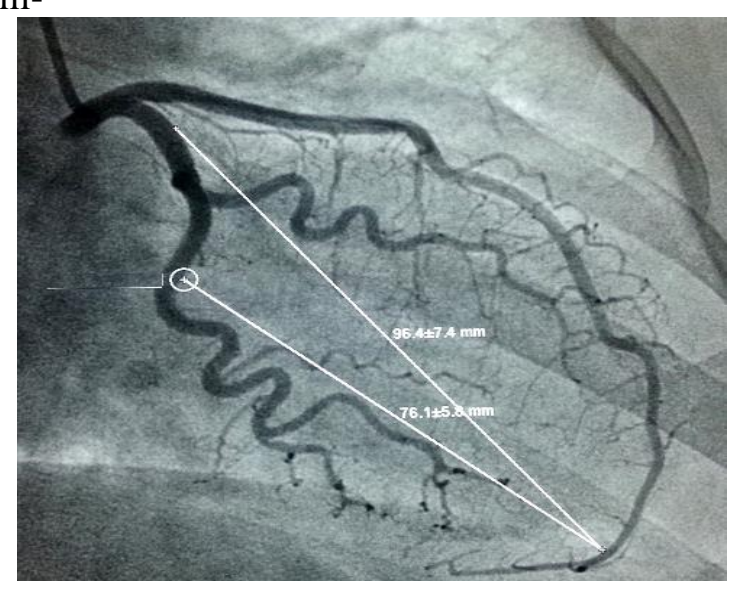

24hours after the PCI procedure to determine the peak concentration for each marker.

5. Coronary angiography and primary PCI: Cannulation and contrast injection were done in the left and right coronary systems using suitable catheters before fixing the culprit lesion in LAD. Balloon predilatation, thrombectomy, stenting technique, and administration of glycoprotein IIb/IIIa receptor inhibitors were left to the operator's discretion. All patients were loaded with dual antiplatelets and were effectively anticoagulated.

6. Assessment of CAM:

The measurement was made in right anterior oblique (RAO) 30 degree projection both at end-diastole and end-systole. The amplitude of CAM was calculated as the difference between these two distances. For each patient 2 measurements were taken:

i- The first measurement from a proximal point on the horizontal part of the Cx artery and the most apical part of LAD artery.

ii- The second measurement from a distal point on the horizontal part of the $\mathrm{Cx}$ artery and the same apical part of LAD artery. The mean of the 2 measurements were taken to represent CAM (Figure 1 ).

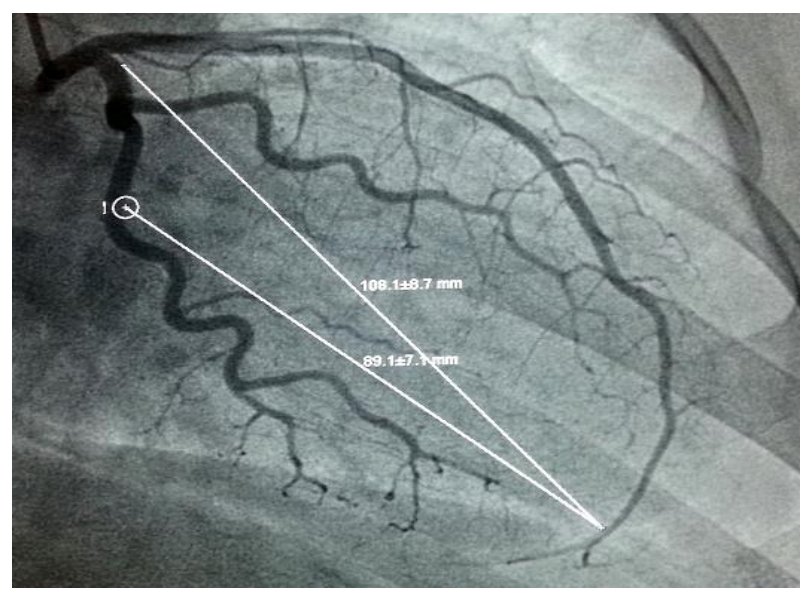

Figure 1: Method of measurement of circumflex artery motion in end-systole (left) and end-diastole (right). CAM= end-diastolic length-end-systolic length.

7. Echocardiographic examination: was done using GE, Vivid E9 machine equipped with a 4 $\mathrm{MHz}$ transducer. The following modalities were used:

a- 2-D echocardiography: to calculate the length of LV long-axis at end-diastole, LV volumes (endsystolic and end-diastolic) and LVEF using the biplane Simpson's technique (22).

b- M-mode echocardiography: to measure mitral annular plane systolic excursion (MAPSE). The
AVP-fractional shortening was calculated by dividing MAPSE by the length of the LV longaxis (23).

c- Color-flow Doppler echocardiography: to assess severity of mitral regurge (MR) semiquantitatively. According to vena contracta width (the narrowest portion of MR jet downstream from the mitral orifice), MR was characterized as: mild (vena cnotracta width $<3 \mathrm{~mm}$ ), moderate (vena 
contracta width 3-6 $\mathrm{mm}$ ) and severe (vena contracta width $\geq 7 \mathrm{~mm}$ ) (24).

d- Tissue Doppler echocardiography: Measurements of peak systolic velocity $\left(S^{\prime}\right)$ at the septal, lateral, inferior, and anterior mitral annulus were taken separately and averaged (25). The degree of LV long-axis dyssynchrony was measured as the maximum difference between Q$S^{\prime}$ intervals from the four sites of mitral annulus. Q-S' intervals represent the time lag between the Q wave in the ECG and peak S' waves (26).

e- Speckle tracking Echocardiography to measure global long-axis peak strain (GLPS):

From optimal 4-chamber, 2-chamber and 3chamber views, global longitudinal peak strain (GLPS) is measured using automated function imaging (AFI). Then, the 3 measurements were averaged (3).

\section{Follow-up:}

All patients were discharged at maximal medical treatment. Clinical evaluation at 2-4-6 months and echocardiographic evaluation at 6 months were done. $\mathrm{A}>10 \%$ reduction in LVESV at 6 months follow-up was used to define reverse remodeling (27).
Intra-observer
and
Inter-observer

Inter-observer variability was calculated through evaluating 10 random patients by 2 experienced independent observers blinded to the study. Intra-observer variability was calculated through evaluating 10 patients by the same observer but at 2 different points of time.

\section{Statistical methods:}

Kolmogorov-Smirnov test was used to confirm normal distribution of continuous variables which were expressed as mean values \pm 1 standard deviation. However, variables not normally distributed were expressed as medians (interquartile ranges). Categorical variables were expressed as absolute numbers and frequency percentages. Patients were dichotomized according to median value of CAM. The Pearson $\chi^{2}$-test, Independent-Samples T-test and MannWhitney U-test were used to compare categorical variables, normally distributed continuous variables and skew-distributed continuous variables; respectively. Receiver operating characteristic (ROC) curve was used to define the CAM cutoff value with best accuracy for prediction of reverse remodeling at the end of follow-up period. $\mathrm{P}$ value $<0.05$ was considered significant.

Variabilities:

RESULTS

The demographic and angiographic characteristics of the study participants are presented in Table $\mathbf{1}$. Table (1): Demographic and angiographic characteristics of the whole study group (50 patients):

\begin{tabular}{|c|c|c|}
\hline \multicolumn{2}{|r|}{ Variables } & \multirow{2}{*}{$\frac{\text { No }(\%)}{57 \pm 8}$} \\
\hline & Age $($ mean \pm SD) $($ years $)$ & \\
\hline \multirow{2}{*}{ Se } & Male & $43(86 \%)$ \\
\hline & Female & $7(14 \%)$ \\
\hline \multirow{4}{*}{ 步 } & Diabetes Mellitus & $28(56 \%)$ \\
\hline & Hypertension & $20(40 \%)$ \\
\hline & Current Smoking & $19(38 \%)$ \\
\hline & Dyslipidemia & $10(20 \%)$ \\
\hline \multirow{3}{*}{ 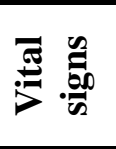 } & Admission heart rate (beats/min) & $92 \pm 20$ \\
\hline & Admission SBP (mmHg) & $135 \pm 28$ \\
\hline & Admission DBP (mmHg) & $83 \pm 12$ \\
\hline \multirow{5}{*}{ 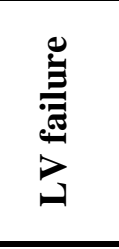 } & NO no $(\%)$ & $24(48 \%)$ \\
\hline & Yes no $(\%)$ & $26(52 \%)$ \\
\hline & Killip class I & $18(69.2 \%)$ \\
\hline & Killip class II & $4(15.4 \%)$ \\
\hline & Killip class III & $4(15.4 \%)$ \\
\hline & Ischemic time (minutes) & $574 \pm 336$ \\
\hline & Peak CK-MB release (ug/L) & $153.9 \pm 67.02$ \\
\hline & Peak troponin release $(\mathrm{ug} / \mathrm{L})$ & $8.69 \pm 3.56$ \\
\hline & CAM (mean \pm SD) $(\mathrm{mm})$ & $14.2 \pm 3.9$ \\
\hline
\end{tabular}

CAM: circumflex artery motion, DBP: diastolic blood pressure, SBP: systolic blood pressure; TIMI: thrombolysis in myocardial infarction. 


\section{Correlation between CAM and echocardiographic measures of LV long-axis function:}

Strong correlation was found between CAM and echocardiographic parameters of LV long-axis systolic function ( $\mathrm{p}$ for each $<0.001)$ as well as LVEF 24 hours after successful primary PCI $(\mathrm{r}=0.845, \mathrm{p}<0.001)$ (Figure 2).
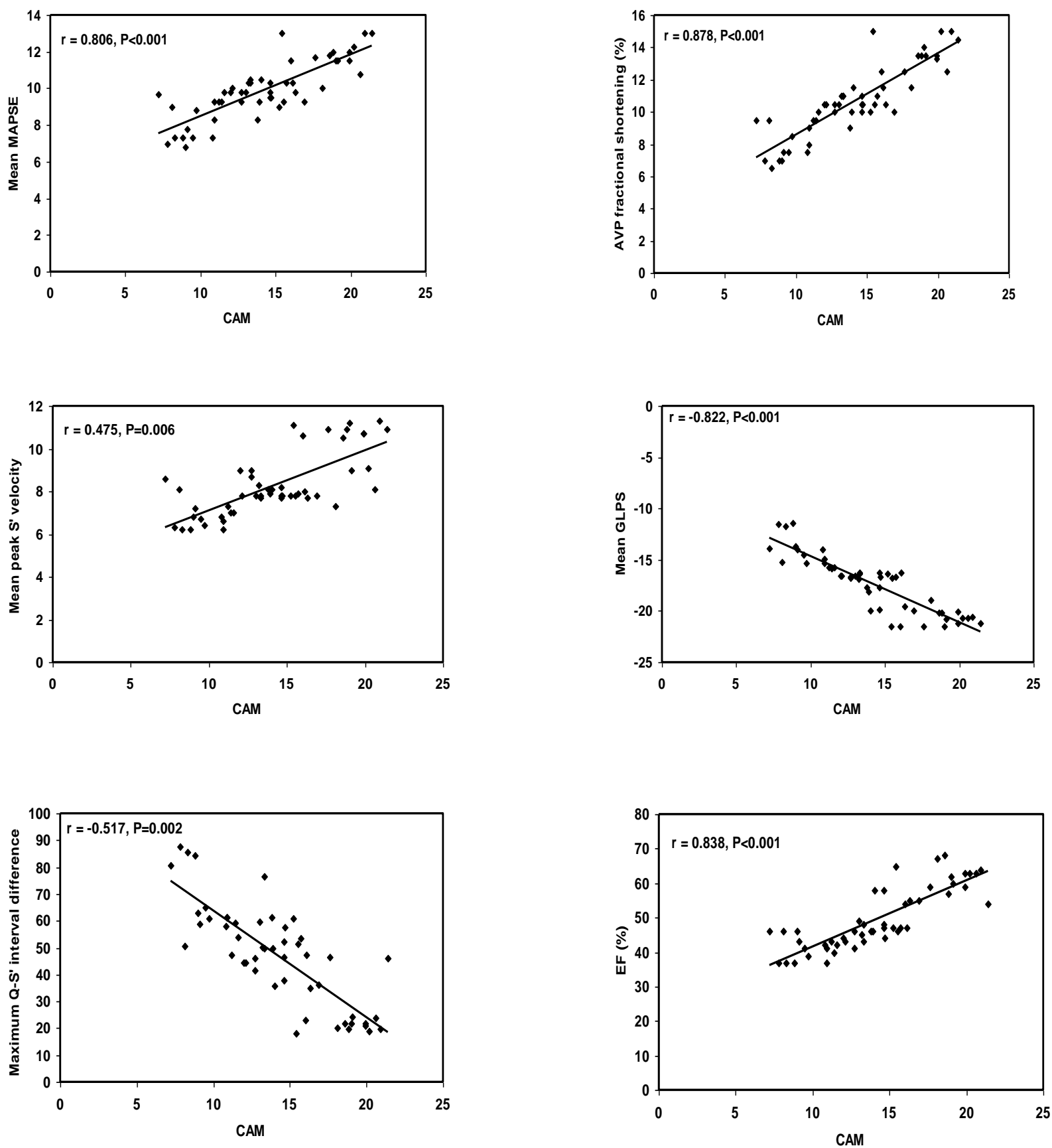

Figure 2: Correlation between CAM and mean MAPSE $(r=8.6, \mathrm{p}<0.001)$, AVP fractional shortening $(\mathrm{r}=$ $0.878, \mathrm{p}<0.001)$, mean peak $\mathrm{S}^{\prime}$ velocity $(\mathrm{r}=0.475, \mathrm{p}=0.006)$, mean GLPS $(\mathrm{r}=-0.822, \mathrm{p}<0.001)$, LV longitudinal systolic dyssynchrony $(r=-0.517, p=0.002)$ and LVEF $(r=0.838, p<0.001)$. AVP: atrioventricular plane, EF: ejection fraction, GLPS: global longitudinal peak strain, MAPSE: mitral annular plane systolic excursion. 
Comparison between the 2 CAM groups:

Patients were divided into 2 groups according to median CAM (median CAM: $13.9 \mathrm{~mm}$ ). Table 2 shows comparison between the 2 CAM groups according to clinical and angiographic data.

Table (2): Comparison between the two CAM groups:

\begin{tabular}{|c|c|c|c|c|c|c|}
\hline \multirow{2}{*}{\multicolumn{2}{|c|}{$\begin{array}{c}\text { Variables } \\
(\text { Mean } \pm \text { SD) }\end{array}$}} & \multicolumn{2}{|c|}{$\begin{array}{c}\text { Infra-median CAM } \\
\qquad(n=24)\end{array}$} & \multicolumn{2}{|c|}{$\begin{array}{c}\text { Supra-median CAM } \\
\qquad(\mathrm{n}=26)\end{array}$} & \multirow[t]{2}{*}{$P$ value } \\
\hline & & No & $\%$ & No & $\%$ & \\
\hline Age (years) & & \multicolumn{2}{|c|}{$59.38 \pm 7.52$} & \multicolumn{2}{|c|}{$55.5 \pm 7.92$} & 0.083 \\
\hline \multirow[b]{2}{*}{ Sex } & Male & 22 & $91.7 \%$ & 21 & $80.8 \%$ & \multirow{2}{*}{0.267} \\
\hline & Female & 2 & $8.3 \%$ & 5 & $19.2 \%$ & \\
\hline \multirow{4}{*}{ 范 } & Diabetes & 18 & $75 \%$ & 10 & $38.5 \%$ & 0.009 \\
\hline & Hypertension & 9 & $3.7 \%$ & 11 & $42.3 \%$ & 0.729 \\
\hline & Current smoking & 9 & $3.7 \%$ & 10 & $38.5 \%$ & 0.944 \\
\hline & Dyslipidemia & 4 & $16.7 \%$ & 6 & $23.1 \%$ & 0.571 \\
\hline \multicolumn{2}{|c|}{ Heart rate (beat/min) } & \multicolumn{2}{|c|}{$102.42 \pm 18.82$} & \multicolumn{2}{|c|}{$82.38 \pm 15.84$} & $<0.001$ \\
\hline \multicolumn{2}{|l|}{ SBP (mmHg) } & \multicolumn{2}{|c|}{$134.58 \pm 29.48$} & \multicolumn{2}{|c|}{$134.62 \pm 27.45$} & 0.997 \\
\hline \multicolumn{2}{|l|}{ DBP (mmHg) } & \multicolumn{2}{|c|}{$82.5 \pm 12.59$} & \multicolumn{2}{|c|}{$83.85 \pm 11.34$} & 0.693 \\
\hline \multicolumn{2}{|l|}{ Killip class $>1$} & 8 & $47 \%$ & 0 & $0 \%$ & 0.047 \\
\hline \multicolumn{2}{|c|}{ Peak CK MB (ug/L) } & \multicolumn{2}{|c|}{$202.39 \pm 48.22$} & \multicolumn{2}{|c|}{$109.19 \pm 48.26$} & $<0.001$ \\
\hline \multicolumn{2}{|c|}{ Peak Treponin (ug/L) } & \multicolumn{2}{|c|}{$11.13 \pm 2.78$} & \multicolumn{2}{|c|}{$6.43 \pm 2.6$} & $<0.001$ \\
\hline Ischemic time & & \multicolumn{2}{|c|}{$864.17 \pm 195.98$} & \multicolumn{2}{|c|}{$301.15 \pm 164.85$} & $<0.001$ \\
\hline \multicolumn{2}{|c|}{ TIMI 3 after PCI } & 8 & $33.3 \%$ & 20 & $76.9 \%$ & 0.002 \\
\hline \multicolumn{2}{|c|}{ ST segment resolution } & 12 & $50 \%$ & 21 & $80.8 \%$ & 0.02 \\
\hline \multirow{3}{*}{ MACE } & Non-fatal MI & 2 & $8.3 \%$ & 0 & $0 \%$ & 0.435 \\
\hline & New CHF & 9 & $37.5 \%$ & 1 & $3.8 \%$ & 0.020 \\
\hline & Composite MCE & 11 & $45.8 \%$ & 1 & $3.8 \%$ & 0.001 \\
\hline
\end{tabular}

CHF: congestive heart failure, CK MB: creatine kinase-myocardial band, DBP: diastolic blood pressure, MACE: major adverse cardiac events, MI: myocardial infarction, PCI: percutaneous coronary intervention, SBP: systolic blood pressure; TIMI: Thrombolysis In Myocardial Infarction.

Prediction of reverse remodeling at 6 months:

By univariate logistic regression of independent predictors of reverse remodeling ( $>$ $10 \%$ reduction in LVESV at 6 months follow-up), we found that CAM, AVP fractional shortening at 24 hours, peak troponin and peak CK-MB predicted reverse remodeling with a highly significant value. Age, admission heart rate and blood pressure, use of thrombectomy, successful ST resolution, mean MAPSE at 24 hours, mean peak $S^{\prime}$ at 24 hours, mean GLPS at 24 hours and LV long-axis systolic synchrony at 24 hours also predicted reverse remodeling with a significant value (Table 3). After multivariate logistic regression, only CAM remained significant (Table 4). To determine a cutoff value for CAM, ROC curve analysis was done (AUC, 0.99; 95\% CI $0.88-1.0, \mathrm{P}<0.0001)$. A cutoff value for CAM of $10.8 \mathrm{~mm}$ was found to be predictive with a sensitivity of $96 \%$ and a specificity of $100 \%$ (Figure 3). 
Table (4): Univariate logistic regression of potential predictors of reverse remodeling 6 months postPPCI:

\begin{tabular}{|c|c|c|c|c|c|}
\hline Variables & $\mathbf{R C}$ & SE & OR & $95 \% \mathrm{CI}$ & $\mathbf{P}$ \\
\hline Gender (male) & +0.747 & 0.405 & 2.111 & $0.955-4.666$ & 0.065 \\
\hline Age & +0.014 & 0.006 & 1.014 & $1.002-1.027$ & 0.027 \\
\hline Heart rate $(\mathrm{b} / \mathrm{min})$ & +0.008 & 0.004 & 1.008 & $1.001-1.016$ & 0.030 \\
\hline SBP (mmHg) & +0.007 & 0.003 & 1.007 & $1.001-1.013$ & 0.017 \\
\hline DBP (mmHg) & +0.012 & 0.005 & 1.012 & $1.002-1.021$ & 0.014 \\
\hline LV failure & +0.916 & 0.483 & 0.058 & $0.970-6.443$ & 0.058 \\
\hline Killip class > I & +1.099 & 1.155 & 3.000 & $0.312-28.841$ & 0.341 \\
\hline Peak CK MB (ug/L) & -0.007 & 0.002 & 0.993 & $0.989-0.997$ & 0.001 \\
\hline Peak Treponin (ug/L) & -0.108 & 0.036 & 0.898 & $0.837-0.898$ & 0.003 \\
\hline Ischemic time (min) & +0.001 & 0.000 & 1.001 & $1.000-1.002$ & 0.109 \\
\hline Thrombectomy & +0.847 & 0.398 & 2.333 & $1.069-5.095$ & 0.033 \\
\hline CAM & +0.110 & 0.037 & 1.116 & $1.038-1.200$ & 0.003 \\
\hline ST resolution & +1.674 & 0.629 & 5.332 & $1.554-18.297$ & 0.008 \\
\hline EDV at $24 \mathrm{~h}$ & +0.005 & 0.003 & 1.005 & $1.000-1.010$ & 0.065 \\
\hline ESV at $24 \mathrm{~h}$ & +0.008 & 0.005 & 1.008 & $0.999-1.018$ & 0.089 \\
\hline MR at $24 \mathrm{~h}$ (mild) & +0.511 & 0.730 & 1.667 & $0.398-6.974$ & 0.484 \\
\hline Mean MAPSE at $24 \mathrm{~h}(\mathrm{~cm})$ & +0.126 & 0.046 & 1.134 & $1.037-1.241$ & 0.006 \\
\hline $\begin{array}{c}\text { AVP fractional shortening } \\
\text { at } 24 \mathrm{~h}(\%)\end{array}$ & +0.127 & 0.045 & 1.135 & $1.040-1.239$ & 0.004 \\
\hline Mean Peak S' at $24 \mathrm{~h}$ & +0.137 & 0.053 & 1.147 & $1.033-1.273$ & 0.010 \\
\hline $\begin{array}{c}\text { Q-S' Maximum difference } \\
\text { at } 24 \mathrm{~h} \\
\end{array}$ & +0.005 & 0.002 & 1.005 & $1.001-1.009$ & 0.019 \\
\hline Mean GLPS at $24 \mathrm{~h}$ & -0.073 & 0.027 & 0.929 & $0.882-0.979$ & 0.006 \\
\hline
\end{tabular}

AVP: atrio-ventricular plane, CAM: circumflex artery motion, CI: confidence interval,CK MB: creatine kinase-myocardial band, DBP: diastolic blood pressure, SBP: systolic blood pressure, EDV: end-diastolic volume, ESV: end-systolic volume, GLPS: global longitudinal peak strain, LV: left ventricle, MAPSE: mitral annular plane systolic excursion, MR: mitral regurgitation, OR: odds ratio, $\mathbf{P}$ value: significance, RC: regression coefficient, $\mathbf{S E}$ : standard error.

Table (5) Multivariate logistic regression of potential predictors of reverse remodeling 6 months post PCI

\begin{tabular}{cccccc}
\hline Variable & RC & SE & OR & 95\% CI & P \\
\hline CAM & +1.8535 & 0.6057 & 6.3822 & $1.9469-20.9216$ & 0.002 \\
\hline
\end{tabular}

CAM: circumflex artery motion, CI: confidence interval, OR: odds ratio, RC: regression coefficient, $\mathbf{P}$ value: significance, SE: standard error. Constant: - 15.6595.

Reproducibility: Interobserver and intraobserver agreement for assessment of CAM was 93\% and 95\%; respectively. 


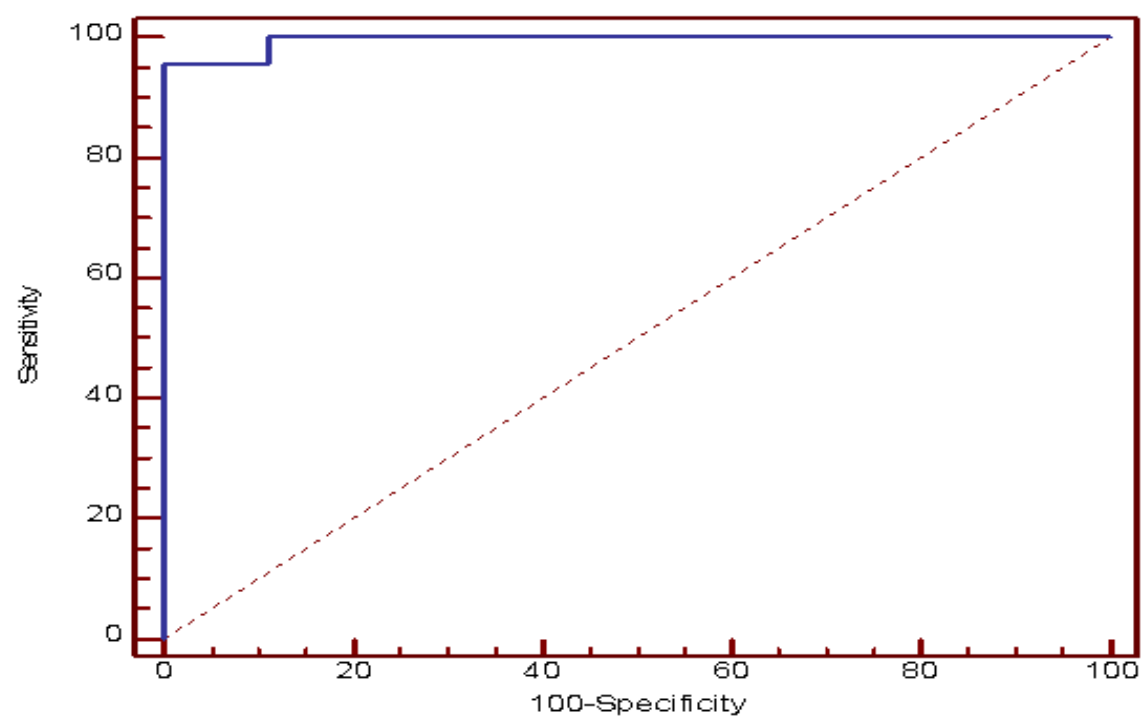

Figure 5: ROC curve of CAM in prediction of reverse remodeling 6 months after primary PCI.

\section{DISCUSSION}

Main findings of the current study are (1) there is strong correlation between CAM and echocardiographic (M-mode, tissue Doppler and speckle tracking) parameters of LV long-axis function, (2) CAM was strongly correlated with LVEF 24 hours after successful primary PCI, and (3) A CAM cutoff value of $10.8 \mathrm{~mm}$ accurately predicted reverse remodeling 6 months after successful primary PCI.

\section{Correlation between CAM and echocardiographic parameters of $L V$ long-axis function:}

In the current study, we found that CAM was strongly correlated with echocardiographic parameters of long-axis LV function. This can be explained by the fact that the first horizontal part of the $\mathrm{Cx}$ artery is situated in the AV groove. Consequently, movement of this part can reflect left AVP displacement towards LV apex. Emilsson K. et al. (20) used the same technique to measure CAM and demonstrated no difference between CAM and mitral annular motion (MAM) both at the level of the lateral part of the annulus and the mean MAM from the four sites of the annulus.

\section{Correlation between CAM and LVEF:}

This study found a significant correlation between CAM and LVEF measured by modified Simpson's method. Furthermore, patients with supra-median CAM tended to have higher LVEF. A similar finding was observed by Kahari A. et al. (32) who found a significant correlation between CAM and LVEF estimated by ventriculography. Many studies support the use of echocardiographic parameters of long-axis LV function as surrogates of global LV function (33, 34).

Correlation between CAM and LV long-axis systolic dyssynchrony:

The study found a significant negative correlation between CAM and LV long-axis systolic dyssynchrony measured as the maximum Q-S' interval difference. LV dyssynchrony have been observed in the setting of STEMI despite normal systolic function and normal QRS duration (35). In addition, it was demonstrated that dyssynchrony associated with STEMI was mainly determined by the infarct size measured by MRI (36). Turan B. et al. (37) demonstrated that after primary $\mathrm{PCI}$, a maximum Q-S' interval difference of $>56$ msec predicts LV remodeling at 6 months with a sensitivity of $73 \%$ and a specificity of $84 \%$.

\section{Comparison between the 2 CAM groups:}

The current study showed that DM was significantly more prevalent in the group with infra-median CAM. Diabetic cardiomyopathy has been defined as a primary myocardial disease in diabetic patients without significant epicardial $\mathrm{CAD}$, hypertension, or valvular heart disease. It is thought to be mediated by myocardial steatosis, microvascular disease, and myocardial fibrosis (38). These changes are reflected on long-axis function as shown in many studies using both tissue Doppler imaging (39) and speckle-tracking imaging (40). 
There was a significant difference between both groups regarding clinical LV failure and Killip class. This is explained by the fact that LV longitudinal function, measured by cardiac magnetic resonance, is the primary contributor to LV function, and accounts for approximately $60 \%$ of the SV (41).

Ischemic time was significantly shorter in the group of supra-median CAM, probably reflecting lesser myocardial damage. This is consistent with the negative correlation between ischemic time and GLPS reported by Bertini M. et al (42). Longer ischemic time will ultimately lead to larger infarct size and limit reverse remodeling (43). In addition, it will lead to a mature fibrinrich thrombus which predisposes to distal embolization and decreases microvascular flow (44).

Peak CK-MB and troponin were significantly higher in the group of infra-median CAM. Higher cardiac biomarkers reflect more sizable infarcts, compromised microvascular perfusion, refractory thrombi, a more thrombophilic milieu and longer ischemic time. These factors would negatively impact on long-axis LV function. Bertini M. et al. (42) and Woo J. et al. (45) reported negative correlation between cardiac biomarkers and GLPS.

After primary PCI, ST segment resolution occurred more in the group of supra-median CAM. ST segment recovery has been shown to be related to cell membrane integrity, myocyte function and tissue level reperfusion (46). Many studies report the strong correlation between ST resolution and long-axis LV function $(47,48)$.

In the current study, TIMI 3 flow was identified in 8 patients $(33.33 \%)$ of infra-median CAM group versus 20 patients $(76.9 \%)$ of supramedian CAM group ( $\mathrm{P}$ value 0.002 ). This may reflect shorter ischemic time, smaller and less mature thrombus, better microvascular preservation, smaller final infarct size and normalized LV mechanics.

\section{Prediction of reverse remodeling at 6 months:}

The current study found that CAM, AVP fractional shortening at 24 hours and peak CK-Mb and troponin level predicted reverse remodeling with a highly significant value. Other echocardiographic parameters of long-axis LV function at 24 hours also predicted reverse remodeling with a significant value. After multivariate logistic regression, only CAM remained significant. A cutoff value for CAM of $10.8 \mathrm{~mm}$ was found to be predictive with a sensitivity of $96 \%$ and a specificity of $100 \%$.
This may be explained by that long-axis LV function is related to final infarct size (16), microvascular occlusion (17) and extent of myocardial viability (18). Collectively, they determine the contractile recovery of LV function after primary PCI.

Peak troponin and CK-MB could significantly predict LV functional recovery at 6 months. This finding support previous findings that peak troponin level strongly predicts the recovery of LV function even more important than any other clinical measure $(49,50)$.

\section{Study Limitations:}

Our findings are restricted to anterior STEMI patients with culprit lesions in LAD treated with primary PCI. So, these results cannot be extrapolated to right coronary or $\mathrm{Cx}$ artery STEMIs. The study included a relatively small number of patients but the 2 CAM groups were matched as regards age, gender and most of risk factors.

The study shows a rather good reproducibility for CAM. In some patients however, this measure cannot be obtained, namely in patients lacking visible branches in the apical region or patients having total occlusion of the proximal horizontal part of the $\mathrm{Cx}$ artery. In addition, it still remains to investigate the validity of CAM in patients with AF, LV hypertrophy and LV aneurysm.

\section{CONCLUSION AND CLINICAL IMPLICATIONS}

CAM measured at time of primary PCI correlates excellently with LVEF and negates the need for "in-lab" echocardiography machine as well as ventriculography. Is also allows rapid assessment of LV function without prolonging the "door-to-balloon" time. Furthermore, it allows prediction of reverse remodeling at 6 months which helps optimizing therapeutic strategies at time of mechanical reperfusion. Use of GP IIb/IIIa receptor inhibitors, thrombectomy and total revascularization are justified in high-risk patients with lower CAM $(<10.8 \mathrm{~mm})$.

\section{REFERENCES}

1. Sengupta PP, Korinek J, Belohlavek M, Narula J, Vannan MA, Jahangir A, Khandheria BK: Left ventricular structure and function: basic science for cardiac imaging. J Am Coll Cardiol 2006;48:1988-2001

2. Yip G., Abraham T., Belohlavek M., Khandheria B.:Clinical applications of strain rate imaging. $\mathrm{J}$ Am Soc Echocardiogr 2003; 16:1334 -42.

3. Mor-Avi V, Lang RM, Badano LP, Belohlavek M, Cardim NM, Derumeaux G, Galderisi M, Marwick T, Nagueh SF, Sengupta PP, Sicari R, Smiseth OA, Smulevitz B, Takeuchi M, Thomas 
JD, Vannan M, Voigt JU, Zamorano JL..:Current and Evolving Echocardiographic Techniques for the Quantitative Evaluation of Cardiac Mechanics: ASE/EAE Consensus Statement on Methodology and Indications Endorsed by the Japanese Society of Echocardiography. J Am Soc Echocardiogr 2011; 24:277-313.

4. Koestenberger M, Nagel B, Ravekes W, Avian A, Heinzl B, Fritsch P, Fandl A, Rehak T, Gamillscheg A:Left ventricular long-axis function: Reference values of the mitral annular plane systolic excursion in 558healthy children and calculation of $\mathrm{z}$-score values. Am Heart J 2012; 164:125-31.

5. Penicka M., Vanderheyden M. and Bartunek J.: Diagnosis of heart failure with preserved ejection fraction: role of clinical Doppler echocardiography. Heart 2014;100:68-76

6. Mazhari R., Omens J., Pavelec R., Covell J., McCulloch A.: Transmural distribution of threedimensional systolic strains in stunned myocardium. Circulation 2001; 104:336-41.

7. Jennings R.: Historical Perspective on the Pathology of Myocardial Ischemia/Reperfusion Injury. Circ Res. 2013;113:428-438

8. Brosh D, Assali AR, Mager A, Porter A, Hasdai D, Teplitsky I, Rechavia E, Fuchs S, Battler A, Kornowski R.: Effect of no-reflow during primary percutaneous coronary intervention for acute myocardial infarction on six-month mortality. Am J Cardiol 2007; 99: 442-5

9. de Boer MJ, Suryapranata H, Hoorntje JC, Reiffers S, Liem AL, Miedema K, Hermens WT, van den Brand MJ, Zijlstra F.: Limitation of infarct size and preservation of left ventricular function after primary coronary angioplasty compared with intravenous streptokinase in acute myocardial infarction. Circulation 1994; 90:75361.

10. Funaro S, La Torre G, Madonna M, Galiuto L, Scarà A, Labbadia A, Canali E, Mattatelli A, Fedele F, Alessandrini F, Crea F, Agati L; AMICI Investigators..: Incidence, determinants, and prognostic value of reverse left ventricular remodeling after primary percutaneous coronary intervention: Results of the Acute Myocardial Infarction Contrast Imaging (AMICI) multicenter study. Eur Heart J2009; 30:566-575.

11. Hamdan A, Kornowski R, Lev EI, Sagie A, Fuchs S, Brosh D, Battler A, Assali AR: Impact of Myocardial Blush on Left Ventricular Remodeling After First Anterior Myocardial Infarction Treated Successfully with Primary Coronary Intervention. IMAJ 2010; 12: 211-215

12. Kim RJ, Wu E, Rafael A, Chen EL, Parker MA, Simonetti O, Klocke FJ, Bonow RO, Judd RM:
The use of contrast-enhanced magnetic resonance imaging to identify reversible myocardial dysfunction. N Engl J Med 2000; 343: 14451453.

13. Nucifora G, Bertini M, Ajmone Marsan N, Scholte AJ, Siebelink HM, Holman ER, Schalij MJ, van der Wall EE, Bax JJ, Delgado V.: Temporal evolution of left ventricular dyssynchrony after myocardial infarction: relation with changes in left ventricular systolic function European Heart Journal - Cardiovascular Imaging 2012; 13, 1041-1046

14. İnci $S$, Karakelleoğlu Ş, Taş $M H$, Arslan Ş, Gündoğdu F, Bakırc1 EM, Değirmenci $H$, Şenocak H..: Acute effect of primary percutaneous coronary intervention on left ventricular dyssynchrony in ST-segment elevation myocardial infarction. Anadolu Kardiyol Derg 2014; 14: 591-8

15. Cha K., Choi JC. and Choi JH.: The Incidence, Clinical Predictors And Prognostic Value of Reverse Left Ventricular Remodeling in Patients With STEMI Undergoing Primary PCI.JACC March 12, 2013 Volume 61, Issue 10. E151.

16. Sjøli B, Ørn S, Grenne B, Ihlen H, Edvardsen T, Brunvand H.: Diagnostic capability and reproducibility of strain by Doppler and by speckle tracking in patients with acute myocardial infarction. JACC Cardiovasc Imaging 2009; 2:2433.

17. Bière L, Donal E, Terrien G, Kervio G, Willoteaux S, Furber A, Prunier F: Long-axis Strain Is a Marker of Microvascular Obstruction and Infarct Size in Patients with Acute STSegment Elevation Myocardial Infarction. PLoS ONE 9(1): e86959.

18. Mollema SA, Delgado V, Bertini M, Antoni ML, Boersma E, Holman ER, Stokkel MP, van der Wall EE, Schalij MJ, Bax JJ..: Viability Assessment With Global Left Ventricular Longaxis Strain Predicts Recovery of Left Ventricular Function After Acute Myocardial Infarction. Circ Cardiovasc Imaging. 2010; 3:15-23.

19. Park YH, Kang SJ, Song JK, Lee EY, Song JM, Kang DH, Kim YH, Lee CW, Hong MK, Kim JJ, Park SW, Park SJ. : Prognostic value of long-axis strain after primary reperfusion therapy in patients with anterior-wall acute myocardial infarction. $\mathbf{J}$ Am Soc Echocardiogr 2008; 21:262-267.

20. Emilsson K., Kahari A. and Wandt B.: Comparison between Circum • ex Artery Motion and Mitral Annulus Motion. Scand Cardiovasc J 2001; 35: 318-325.

21. Grundy SM, Cleeman JI, Merz CN, Brewer HB Jr, Clark LT, Hunninghake DB, Pasternak RC, 
Smith SC Jr, Stone NJ: Implications of recent clinical trials for the national cholesterol education program adult treatment panel III guidelines. Circulation2004; 110:227-239.

22. Lang RM, Bierig M, Devereux RB, Flachskampf FA, Foster E, Pellikka PA, Picard MH, Roman MJ, Seward J, Shanewise JS, Solomon SD, Spencer KT, Sutton MS, Stewart WJ: Recommendations for chamber quantification: A Report from the American Society of Echocardiography's Guidelines and Standards Committee and the Chamber Quantification Writing Group, Developed in Conjunction with the European Association of Echocardiography, a Branch of the European Society of Cardiology. J Am Soc Echocardiogr2005; 18:1440-1463.

23. Willenheimer R, Rydberg E, Stagmo M, Gudmundsson P, Ericsson G, Erhardt L: Echocardiographic assessment of left atrioventricular plane displacement as a complement to left ventricular regional wall motion evaluation in the detection of myocardial dysfunction. Int $\mathrm{J}$ Cardiovasc Imaging 2002;18:181-6.

24. Grayburn P., Weissman N. and Zamorano J.: Quantitation of Mitral Regurgitation. Circulation. 2012; 126:2005-2017.

25. Srivasta P., Burrell L. and Calafiore P.: Lateral vs. medial mitral in the echocardiographic annular tissue Doppler assessment of diastolic function and filling pressures: which should we use? Eur J echocardiography 2005; 6: 97-106

26. Ko JS, Jeong MH, Lee MG, Lee SE, Kang WY, Kim SH, Park KH, Sim DS, Yoon NS, Yoon HJ, Hong YJ, Park HW, Kim JH, Ahn Y, Cho JG, Park JC, Kang JC: Left Ventricular Dyssynchrony After Acute Myocardial Infarction is a Powerful Indicator of Left Ventricular Remodeling. Korean Circ J 2009;39:236-242

27. DeGeare VS, Boura JA, Grines LL, O'Neill WW, Grines CL: Predictive value of the Killip classification in patients undergoing primary percutaneous coronary intervention for acute myocardial infarction.Am J Cardiol. 2001 1; 87(9):1035-8.

28. Reant $\mathrm{P}$, Labrousse L, Lafitte $\mathrm{S}$, Bordachar $\mathrm{P}$, Pillois X, Tariosse L, Bonoron-Adele S, Padois P, Deville C, Roudaut R, Dos Santos P.: Experimental validation of circumferential, longaxis, and radial 2-dimensional strain during dobutamine stress echocardiography in ischemic conditions. J Am Coll Cardiol 2008; 51: 149-157.

29. Buckberg G., Hoffman J., Mahajan A., Saleh S. and Coghlan C: FunctionCardiac Mechanics Revisited: The Relationship of Cardiac
Architecture to Ventricular. Circulation. 2008;118:2571-2587

30. Antoni ML, Mollema SA, Delgado V, Atary JZ, Borleffs CJ, Boersma E, Holman ER, van der Wall EE, Schalij MJ, Bax JJ.: Prognostic importance of strain and strain rate after acute myocardialinfarction. Eur Heart J 2010; 31:16401647.

31. Caracciolo G, Eleid MF, Abe H, Bhatia N, Fortuin FD, Wilansky S, Carerj S, Sengupta PP.: Non-uniform recovery of left ventricular transmural mechanics in ST-segment elevation myocardial infarction. Cardiovascular Ultrasound 2010, 8:31

32. Kahari A, Emilsson $\mathrm{K}$, Danielewicz $\mathrm{M}$, Andersson T, Wandt B. Circumflex artery motion; A new angiographic method for assessment of left ventricular function. Scand Cardiovasc J 2003; 37: 80-86

33. Matos J., Kronzon I., Panagopoulos G.,Perk G.: Mitral annular plane systolic excursion as a surrogate for left ventricular ejection fraction. J Am Soc Echocardiogr 2012; 25:969-74.

34. Brown J., Jenkins C., Marwick T.: Use of myocardial strain to assess global left ventricular function: a comparison with cardiac magnetic resonance and 3-dimensional echocardiography. Am Heart J. 2009; 157 (1):102 e1-5.

35. Elnoamany MF, Badran $\mathrm{M}$, Abo Elazm $\mathrm{H}$, Abdelaziz S: Asynchrony of left ventricular systolic performance after the first acute myocardial infarction in patients with narrow QRS complexes: Doppler tissue imaging study. J Am Soc Echocardiogr 2006; 19:1449-1457.

36. Nucifora G, Bertini M, Marsan NA, Delgado V, Scholte AJ, Ng AC, van Werkhoven JM, Siebelink HM, Holman ER, Schalij MJ, van der Wall EE, Bax JJ: Impact of left ventricular dyssynchrony early on left ventricular function after first acute myocardial infarction. Am J Cardiol 2010; 105:306-311.

37. Burak Turan, M.D., Fatih Yilmaz, M.D., Tansu Karaahmet, M.D., Kursat Tigen, M.D., Bulent Mutlu, M.D.,and Yelda Basaran: Role of Left Ventricular Dyssynchrony in Predicting Remodeling after ST Elevation Myocardial Infarction. Echocardiography 2012;29:165-172

38. $\mathrm{Ng} \mathrm{AC}$, Delgado V, Bertini M, van der Meer RW, Rijzewijk LJ, Hooi Ewe S, Siebelink HM, Smit JW, Diamant M, Romijn JA, de Roos A, Leung DY, Lamb HJ, Bax JJ. Myocardial steatosis and biventricular strain and strain rate imaging in patients with type 2 diabetes mellitus. Circulation 2010; 122:2538-44.

39. Stefanidis A, Bousboulas S, Kalafatis J, Baroutsi $\mathrm{K}$, Margos $\mathrm{P}$, Komninos $\mathrm{K}$, Pappas $\mathrm{S}$, 
Papasteriadis E. Left ventricular anatomical and functional changes with ageing in type 2 diabetic adults. Eur J Echocardiogr 2009; 10: 647-653

40. Nakai H, Takeuchi M, Nishikage T, Lang RM, Otsuji Y. Subclinical left ventricular dysfunction in asymptomatic diabetic patients assessed by two-dimensional speckle tracking echocardiography: correlation with diabetic duration. Eur J Echocardiogr 2009; 10: 926-932

41. Carlsson M, Ugander M, Mosén H, Buhre $T$, Arheden H.: Atrioventricular plane displacement is the major contributor to left ventricular pumping in healthy adults, athletes, and patients with dilated cardiomyopathy. Am J Physiol Heart Circ Physiol. 2007 ; 292(3):H1452-9

42. Bertini M, Mollema SA, Delgado V, Antoni ML, Ng AC, Holman ER, Boriani G, Schalij MJ, Bax JJ. Impact of time to reperfusion after acute myocardial infarction on myocardial damage assessed by left ventricular long-axis strain. Am J Cardiol 2009;104:480-5

43. Gibson C., de Lemos J., Antman E.: Time is muscle in primary PCI: the strength of the evidence grows. Eur Heart J 2004; 25(12):1001-2.

44. Silvain J, Collet JP, Nagaswami C, Beygui F, Edmondson KE, Bellemain-Appaix A, Cayla G, Pena A, Brugier D, Barthelemy O, Montalescot G, Weisel JW Composition of coronary thrombus in acute myocardial infarction. J Am Coll Cardiol 2011;57(12):1359-67

45. Woo J., Kim W., Yu T, Ha S., Kim S, Bae J, Kim K.: Prognostic Value of Serial Global Long-axis Strain Measured by 3-Dimensional Speckle Tracking Echocardiography in Patients With STSegment Elevation Myocardial Infarction. Am J Cardiol 2011;108:340-347

46. Kleber A.: ST-segment elevation in the electrocardiogram: a sign of myocardial ischemia. Cardiovasc Res 2000; 45:111-118.

47. Ding S., Zhao H., Qiao Z., yang F., Wang W., Gao L., Kong L., Xu R., Ge H., Shen X., Pu J. and He B.: Early resolution of ST-segment elevation after reperfusion therapy for acute myocardial infarction: its relation to echocardiographydetermined left ventricular global and regional function and deformation. Journal of electrocardiology 2014. (article in press) (http://dx.doi.org/10.1016/j.jelectrocard.2014.12.0 03)

48. Darahim K., Mahdy MM, Ryan MM, Hassan OM, Thabet SS, Abdelhamid MA: Intracoronary adenosine as an adjunct to primary coronary intervention in acute myocardial infarction. Journal of the Saudi Heart Association 2013; 25 (2):139
49. Ndrepepa G, Mehilli J, Martino $\Varangle$ S, Schwaiger M, Schomig A, Kastrati A.: Evolution of left ventricular ejection fraction and its relationship to infarct size after acute myocardial infarction. $\mathrm{J}$ Am Coll Cardiol 2007;50:149-56

50. Oh P., Choi I., Ahn T., Moon J., Park Y., Seo J., Suh S., Ahn Y., Jeong M.: Predictors of Recovery of Left Ventricular Systolic Dysfunction after Acute Myocardial Infarction: From the Korean Acute Myocardial Infarction Registry and Korean Myocardial Infarction Registry. Korean Circ J 2013;43:527-533. 